\title{
Neonatal Immune Tolerance Induction to Allow Long-Term Studies With an Immunogenic Therapeutic Monoclonal Antibody in Mice
}

\author{
Matthieu Piccand, ${ }^{1}$ Juliana Bessa, ${ }^{1}$ Eginhard Schick, ${ }^{1}$ Claudia Senn, ${ }^{1}$ \\ Carole Bourquin, ${ }^{2}$ and Wolfgang F. Richter ${ }^{1,3,4}$
}

Received 11 September 2015; accepted 16 November 2015; published online 24 November 2015

\begin{abstract}
The purpose of this study is to test the feasibility of neonatal immune tolerance induction in mice to enable long-term pharmacokinetic studies with immunogenic therapeutic monoclonal antibodies $(\mathrm{mAb})$. Neonatal immune tolerance was induced by transfer of a mAb to neonatal mice via colostrum from nursing mother mice treated with two subcutaneous doses of a tolerogen starting within the first $24 \mathrm{~h}$ after delivery. Adalimumab and efalizumab were administered as tolerogens at various dose levels. Tolerance induction was evaluated in the offspring after reaching adulthood at 8 weeks of age. After a single intravenous injection of the same $\mathrm{mAb}$ as used for tolerance induction, the pharmacokinetics of the $\mathrm{mAb}$ and formation of anti-drug antibodies (ADA) in plasma were assessed using ELISA. Tolerance induction to adalimumab was achieved in a maternal dose-dependent manner. Adalimumab immunetolerant offspring showed a slower adalimumab clearance $(4.24 \pm 0.32 \mathrm{~mL} / \mathrm{day} / \mathrm{kg})$ as compared to the control group $(12.09 \pm 3.81 \mathrm{~mL} / \mathrm{day} / \mathrm{kg})$. In the control group, accelerated clearance started 7 days after adalimumab dosing, whereas immune-tolerant offspring showed a log-linear terminal concentration-time course. In the offspring, the absence of predose ADA levels was indicative of successful tolerance induction. The second test compound efalizumab was not immunogenic in mice under our experimental conditions. Overall, the present study demonstrated the suitability of neonatal immune tolerance induction for a 4-week single dose study in adult mice with a human therapeutic $\mathrm{mAb}$ that is otherwise immunogenic in laboratory animals.
\end{abstract}

KEY WORDS: anti-drug antibodies; clearance change; neonatal immune tolerance induction; tolerogen.

\section{INTRODUCTION}

The interest in therapeutic biologics has been growing over the last two decades. During research and early development of new therapeutic biologics, animal studies are required to assess their efficacy, pharmacokinetic (PK) and pharmacodynamic (PD) properties, and safety. Since therapeutic biologics are usually human or humanized proteins, they can be perceived as foreign in nonclinical species and elicit an immune response (1). The immune response usually leads to the formation of drug-specific antidrug antibodies (ADA) - the measurable hallmark of immunogenicity. The formation of ADA can have impact on safety, efficacy, and PK of a therapeutic protein. ADA-driven effects

\footnotetext{
$\overline{{ }^{1} \text { Roche Pharmaceutical Research and Early Development, }}$ Pharmaceutical Sciences, Roche Innovation Center Basel, Basel, Switzerland.

${ }^{2}$ Department of Medicine, Université de Fribourg, Chemin du Musée 5, 1700, Fribourg, Switzerland.

${ }^{3}$ Roche Pharmaceutical Research and Early Development, Pharmaceutical Sciences, Roche Innovation Center Basel, F. Hoffmann-La Roche Ltd., Grenzacherstrasse 124, 4070, Basel, Switzerland.

${ }^{4}$ To whom correspondence should be addressed. (e-mail: wolfgang.richter@roche.com)
}

on safety include hypersensitivity reactions $(1,2)$, whereas the efficacy of the therapeutic protein can be affected in two different ways: either by reducing or eliminating its biological activity or by changing its PK properties and thus altering exposure. The former effect is caused by ADA binding to the epitopes on the therapeutic protein that are essential for biological activity (so-called neutralizing antibodies), while all ADA, both neutralizing and non-neutralizing, may change clearance of the therapeutic protein. Such change in clearance alters the exposure to the therapeutic protein and thus its efficacy. For most therapeutic proteins, including monoclonal antibodies (mAb), ADA formation increases clearance (3-5); for smaller therapeutic proteins, complexation with ADA can decrease clearance $(6,7)$.

Thus, the immune response in animals can alter the outcome of animal studies and even prevent the conduct of long-term animal studies. In this context, studies are considered long-term, if their duration exceeds a 7 to 10 days-period usually needed for induction of an immune response in laboratory animals $(3,5)$. On the other hand, immunogenicity of human/humanized proteins in animals is considered to be irrelevant for predicting potential immunogenicity in humans (8). Therefore, suppression of an immune response in animal studies can often be beneficial for the translation of animal study results with human/humanized proteins to humans. For 
instance, due to the early onset of the immune-mediated clearance in PK studies, often after only 7 to 10 days $(3,5)$, the PK of immunogenic $m A$ bs sometimes can only be followed over one half-life or less, which leads to uncertainty in PK parameter estimates.

Several approaches have been described for suppression of the immune response in animal models. Cyclosporine, mycophenolic acid, FK506, anti-CD4 antibodies or combinations thereof have been used for this purpose, particularly in studies aimed to prevent allograft rejection in animals (9-11). For studies in mice, the use of severe combined immunodeficiency (SCID) mice can be an alternative to conduct studies without interference from an immune response. Both approaches involve general inhibition of the immune system, which can be disadvantageous in studies requiring a fully functional immune system. An alternative approach, which does not interfere with the overall functionality of the immune system, is to use human immunoglobulin G1 (IgG1) immune-tolerant mouse. Recently, we reported the generation of human IgG1 immune-tolerant mice expressing an Ig minirepertoire (12). These mice are immune-tolerant to a broad range of $\mathrm{IgG1} \mathrm{mAbs}$ and, therefore, can be used for long-term PK studies with several mAbs. However, highly immunogenic mAbs, such as adalimumab, were not tolerated by our transgenic mouse model (unpublished data). Another alternative method is the antigen-specific tolerance induction, which also does not interfere with the overall functionality of the immune system. Intravenous (IV) injection of a high dose of a soluble antigen was shown to induce a state of long-lasting, antigen-specific immune tolerance (high-dose immune tolerance) (13). This approach has been successfully used to enable a safety study with an immunogenic mAb in mice (14). However, high-dose immune tolerance induction is not applicable for studies in which low-single dose is used or necessary dose levels cannot be reached. An alternative antigen-specific approach is neonatal immune tolerance induction $(15,16)$. Exposure of newborns to a tolerogen may render them immune tolerant to the tolerogen. In rodents, the exposure of suckling pups to a tolerogenic IgG can be accomplished via its administration to nursing mothers, with subsequent milk excretion of the $\operatorname{IgG}$ and intestinal absorption in neonates via the neonatal $\mathrm{Fc}$ receptor (FcRn). Although this approach is well established in the literature, it has obviously not yet been used for tolerance induction in long-term studies with therapeutic biologics.

In this study, we aimed at proving the feasibility of neonatal immune tolerance induction in mice using adalimumab (Humira ${ }^{\circledR}$ ) and efalizumab (Raptiva ${ }^{\circledR}$ ) as test compounds. Adalimumab, a human anti-tumor necrosis factor $\alpha \mathrm{mAb}$, is highly immunogenic in laboratory animals. Immunogenicity has been observed following single administration to mice, minipigs, and cynomolgus monkeys ( $\mathrm{F}$. Hoffmann-La Roche, unpublished data; 5,17). Efalizumab, a humanized anti-CD11a antibody, was found immunogenic following multiple administrations to mice (F. Hoffmann-La Roche, unpublished data). Both compounds are not crossreactive in mice. Therefore, neither pharmacokinetics nor immunogenicity is influenced by binding to the respective target.
In the present paper, we demonstrate the feasibility of a compound-specific neonatal immune tolerance induction for adalimumab in mice, which allowed us to conduct a single dose PK study over 4 weeks without impediment from an immune response. Efalizumab failed to be immunogenic under our experimental conditions so that tolerance induction could not be demonstrated.

\section{MATERIALS AND METHODS}

Animals and Test Substances. Pregnant C57BL/6J inbred mice were obtained from Janvier (Route des Chênes Secs, le Genest St Isle, France). Adalimumab (Humira®) was obtained from commercial sources. Efalizumab (Raptiva ${ }^{\circledR}$ ) was obtained from Genentech Inc. (South San Francisco, USA).

Immune Tolerance Induction. Nursing mice (2-3 per dose group) received two doses of either adalimumab (1, 3, 12 , or $40 \mathrm{mg} / \mathrm{kg}$ ) or efalizumab (12 or $160 \mathrm{mg} / \mathrm{kg}$ ) via subcutaneous injection in the interscapular area. The first dose was administered within $24 \mathrm{~h}$ after delivery, and the second dose was given $48 \mathrm{~h}$ after the first dose. Nursing mice of the control groups received no treatment. The mice were kept with their pups in separate cages during 22 lactating days with free access to food and water. Thereafter, a terminal blood sample was collected from the mothers for ADA determination, the mothers were sacrificed, and the offspring were placed in separate cages according to maternal dose and gender.

Pharmacokinetic Studies in Offspring to Test Immune Tolerance Induction. At about 8 weeks after birth, immune tolerance induction was assessed by conducting a PK study in offspring animals weighing between 18 and $25 \mathrm{~g}$. Both male and female animals were used for this study (see Table I). The offspring received a single intravenous dose of either adalimumab $(5 \mathrm{mg} / \mathrm{kg})$ or efalizumab $(2 \mathrm{mg} / \mathrm{kg})$ injected into the tail vein ( $n=5-8 /$ dose group; Table I).

Serial samples of blood $(20 \mu \mathrm{l})$ were collected from each animal at $30 \mathrm{~min}$ before the injection and $5 \mathrm{~min}, 7,24,48,72$, $168 \mathrm{~h}$ and then weekly for up to 4 weeks after the injection. Blood was collected from the tail vein using K3-EDTA microcapillaries (Minivette ${ }^{\circledR}$, Sarstedt AG\&Co, Nümbrecht, Germany). Plasma was separated by centrifugation, and samples were stored at $-20^{\circ} \mathrm{C}$ until analysis. All animal experiments were conducted according to applicable guidelines and approved by Swiss authority. The animal laboratory is AAALAC accredited.

Total mAb Assay. Total mAb concentrations were measured with a generic enzyme-linked immunosorbent assay (ELISA) (18). The assay was performed in streptavidincoated 96 well microplates using biotinylated and digoxigenylated mouse monoclonal anti-human Fc $\gamma$ antibodies as capture and detection reagents. Quality control (QC) samples, calibration standards, and study samples were analyzed at a constant plasma concentration of $5 \%$ and the working range of the assay was between 0.006 and $0.4 \mu \mathrm{g} / \mathrm{mL}$. A 4 parameter logistic function was fitted to the calibration 
Table I. Overview on Mouse In Vivo Studies

\begin{tabular}{|c|c|c|c|c|}
\hline \multicolumn{2}{|c|}{ Tolerance induction in lactating mice } & \multicolumn{3}{|l|}{ PK study in offspring } \\
\hline mAb tolerogen & Dose $(\mathrm{mg} / \mathrm{kg})^{\mathrm{a}}$ & Offspring (males/females) / mother mice & $\mathrm{mAb}$ for $\mathrm{PK}$ & Dose $(\mathrm{mg} / \mathrm{kg})$ \\
\hline \multirow[t]{5}{*}{ Adalimumab } & $-{ }^{\mathrm{b}}$ & $8(8 \mathrm{M} / 0 \mathrm{~F}) / 3$ & Adalimumab & 5 \\
\hline & 1 & $8(8 \mathrm{M} / 0 \mathrm{~F}) / 3$ & Adalimumab & 5 \\
\hline & 3 & $8(8 \mathrm{M} / 0 \mathrm{~F}) / 3$ & Adalimumab & 5 \\
\hline & 12 & $6(3 \mathrm{M} / 3 \mathrm{~F}) / 2$ & Adalimumab & 5 \\
\hline & 40 & $6(3 \mathrm{M} / 3 \mathrm{~F}) / 2$ & Adalimumab & 5 \\
\hline \multirow[t]{4}{*}{ Efalizumab } & $-{ }^{\mathrm{b}}$ & $5(3 \mathrm{M} / 2 \mathrm{~F}) / 1$ & Efalizumab & 2 \\
\hline & 12 & $6(2 \mathrm{M} / 4 \mathrm{~F}) / 2$ & Efalizumab & 2 \\
\hline & 160 & $6(3 \mathrm{M} / 3 \mathrm{~F}) / 2$ & Efalizumab & 2 \\
\hline & 160 & $6(1 \mathrm{M} / 5 \mathrm{~F}) / 2$ & Adalimumab $^{\mathrm{c}}$ & 5 \\
\hline
\end{tabular}

$F$ female, $M$ male, $m A b$ monoclonal antibody, $P K$ pharmacokinetics

${ }^{a}$ Two subcutaneous administrations (within $24 \mathrm{~h}$ after delivery and $48 \mathrm{~h}$ after the first dose)

${ }^{b}$ Control

${ }^{c}$ Compound specificity control

standard data; QC and study sample concentrations were determined by interpolation.

Generic Anti-drug Antibody Assay. Anti-drug antibodies (ADA) were analyzed with a generic ADA assay in streptavidin-coated 96 well microplates as described by Stubenrauch et al. (19). In this sandwich-ELISA, ADAs are converted to immune complexes by pre-incubation with excess drug. A biotinylated mouse anti-human Fab constant domain Fab was used as capture reagent. Detection of bound immune complexes was accomplished with a peroxidaselabeled rabbit anti-murine $\mathrm{Fc}$ antibody. A conjugate consisting of human Fab and murine IgG was used as positive control and for calibration. The assay was conducted in $2 \%$ mouse plasma. The cut point was defined as the lower limit of quantification and corresponded to a concentration of $0.125 \mu \mathrm{g} / \mathrm{mL}$ of the positive control (calibration range $0.125-$ $1.875 \mu \mathrm{g} / \mathrm{mL}$ ). A 4 parameter logistic function was fitted to the calibration standard data, QC, and study sample concentrations were determined by interpolation. Quantitative results for study samples are based on the used positive control and are given in $\mu$ g-equivalent $/ \mathrm{mL}$.

Pharmacokinetic Evaluation. PK parameters were estimated by standard non-compartmental analysis using the pharmacokinetic evaluation program Phoenix WinNonlin 6.2 (Pharsight, USA). Individual plasma concentration-time profiles were used for parameter estimation. The maximum plasma drug concentration (Cmax) was determined directly from the plasma concentration-time profiles. The area under the concentration-time curve from zero to the last measurable concentration (AUClast) was calculated by linear trapezoidal rule. The AUC from time zero to infinity (AUCinf) was calculated from AUClast with extrapolation of the terminal portion of the concentration-time curve from the last measurable concentration to infinity using the apparent terminal elimination rate $(\lambda z) . \lambda z$ was obtained by log-linear regression of the terminal phase of the plasma concentrationtime curve (time period for assessment: 72-672 $\mathrm{h}$ for animals without apparent accelerated decline, $336 \mathrm{~h}$ to the last measurable time point for animals with apparent accelerated decline). Clearance (CL) was calculated as
dose/AUCinf. The apparent terminal half-life (T1/2) was derived as $\mathrm{T} 1 / 2=\ln 2 / \lambda \mathrm{z}$.

Statistical Analysis. Statistical analysis of the PK parameters CL and T1/2 was performed using GraphPad Prism Version 6.0 (GraphPad Software Inc., La Jolla, USA) by oneway ANOVA followed by Dunnett's multiple comparison test. Predose ADA levels were correlated with AUC values by Spearman rank correlation.

\section{RESULTS}

\section{Treatment of Dams}

Two subcutaneous doses of $1,3,12$, or $40 \mathrm{mg} / \mathrm{kg}$ adalimumab or 12 or $160 \mathrm{mg} / \mathrm{kg}$ efalizumab were well tolerated in the mother mice. The litter size ranged between 4 and 9, and most offspring grew normally in all treatment groups. Terminal samples from all mothers treated with adalimumab were tested positive $(>1.875 \mu$ g-equivalent $/ \mathrm{mL}$ ) for ADA (mother mice treated with efalizumab were not tested for ADA).

\section{Pharmacokinetics of Adalimumab in Offspring}

The mean plasma concentration-time curves of adalimumab (5 mg/kg) in the offspring of adalimumabtreated mothers differed markedly from that of the control group (Fig. 1). In the control group, an accelerated decline of the plasma concentration started on day 7 after administration, whereas such acceleration was not apparent in the 1 and $3 \mathrm{mg} / \mathrm{kg}$ groups until day 14 . We observed no accelerated decline in the $12 \mathrm{mg} / \mathrm{kg}$ group, in which adalimumab plasma concentration declined in a log-linear fashion until the end of the study. In the $40 \mathrm{mg} / \mathrm{kg}$ group, three $(50 \%)$ mice showed no indication of the accelerated decline, while in three other mice the accelerated decline started after day 7 or day 21 (data not shown).

The PK profiles of adalimumab were in line with the terminal ADA concentration in the offspring. The ADA 


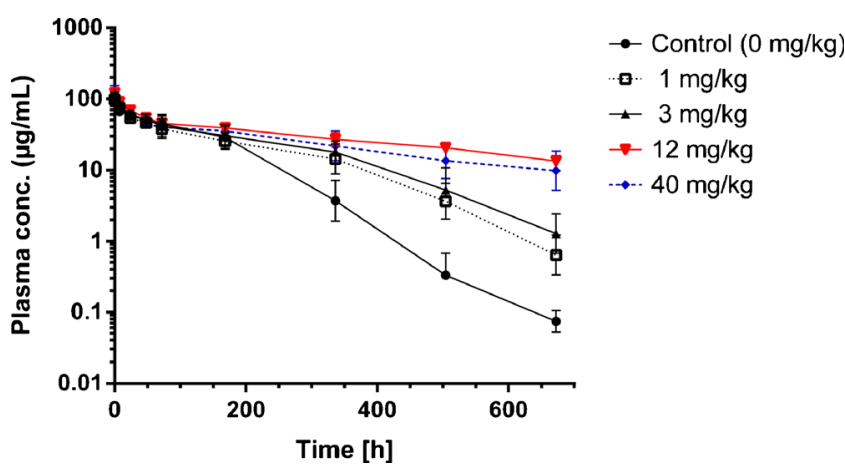

Fig. 1. Mean plasma concentration-time curves of adalimumab following intravenous administration of $5 \mathrm{mg} / \mathrm{kg}$ to the offspring from mother mice treated with two subcutaneous doses of 0 (control), 1, 3, 12 , and $40 \mathrm{mg} / \mathrm{kg}$ adalimumab administered after delivery (mean $\pm \mathrm{SD}$, $n=6-8$ /group)

concentration was the highest in the control group (range 83.4 to 184 ; mean $121 \mu \mathrm{g}$-equivalent $/ \mathrm{mL}$ ) followed by the $1 \mathrm{mg} / \mathrm{kg}$ group (mean $69.7 \mu$ g-equivalent $/ \mathrm{mL}$ ) and the $3 \mathrm{mg} / \mathrm{kg}$ group (mean $42.7 \mu$ g-equivalent $/ \mathrm{mL}$ ). All mice from the $12 \mathrm{mg} / \mathrm{kg}$ group were tested negative for ADA. In the $40 \mathrm{mg} / \mathrm{kg}$ group, only those mice that showed log-linear terminal PK profile had no detectable ADA, whereas all mice having the accelerated decline were ADA-positive (range 0.79 to $8.08 \mu$ g-equivalent/mL).

Pharmacokinetic parameters for adalimumab differed between the groups (Table II and Fig. 2). Mean clearance decreased and mean apparent terminal half-life increased with increasing maternal dose of adalimumab, with the $12 \mathrm{mg} / \mathrm{kg}$ group showing minimal clearance and maximal half-life; the differences from the control group were significant in the 12 and $40 \mathrm{mg} / \mathrm{kg}$ groups. The marked interindividual variability in the $40 \mathrm{mg} / \mathrm{kg}$ group was also evident for PK parameters: the three ADA-negative mice from this group showed clearance similar to that of the $12 \mathrm{mg} / \mathrm{kg}$ group (range 3.35 to $4.04 \mathrm{~mL} / \mathrm{day} / \mathrm{kg}$ ), whereas clearance in the other, ADA-positive, mice was between 5.49 and $14.5 \mathrm{~mL} /$ day/kg (see also Fig. 2). In some dose groups, both male and female animals were used (Table I); since we did not observe any obvious sex differences in PK, data from these animals were pooled.

To evaluate possible correlation with PK results, we determined ADA levels before adalimumab administration in the offspring. The predose ADA levels in the offspring were inversely correlated with the AUClast (Fig. 3). Detectable predose ADA levels were observed in all offspring that were tested positive in the terminal ADA samples, i.e., in all offspring from the 1 and $3 \mathrm{mg} / \mathrm{kg}$ groups (mean 1.39 and $0.967 \mu$ g-equivalent $/ \mathrm{mL}$, respectively) as well as in the three ADA-positive mice in the $40 \mathrm{mg} / \mathrm{kg}$ group (Fig. 4). Of these three mice, one showed a relatively low predose ADA level (0.422 $\mu$ g-equivalent $/ \mathrm{mL})$, whereas one animal had the highest predose ADA level among all tested animals (5.012 $\mu$ g-equivalent $/ \mathrm{mL})$.

\section{Pharmacokinetics of Efalizumab in Offspring}

The mean plasma concentration-time curves of efalizumab (2 $\mathrm{mg} / \mathrm{kg})$ in the offspring from the control and efalizumab-treated mothers were all similar with a log-linear elimination phase and no indication of accelerated clearance (Fig. 5). We found no marked differences in clearance, with mean ( \pm standard deviation) clearance being $4.44 \pm 0.58$ (control), $4.37 \pm 0.50$ (12 mg/kg group), and $3.31 \pm 0.47 \mathrm{~mL} / \mathrm{day} / \mathrm{kg}$ (160 mg/kg group).

In agreement with the PK data, predose as well as terminal study samples of all offspring from efalizumabtreated mothers were tested negative for ADA.

\section{Compound Specificity of Immune Tolerance Induction}

To test the specificity of immune tolerance induction, we administered adalimumab to the offspring of efalizumab-treated $(160 \mathrm{mg} / \mathrm{kg}$ ) mothers (Fig. 5). Similar to the adalimumab control group, the adalimumab plasma concentration-time curve in these offspring showed an accelerated decline starting 7 days after administration. Accordingly, mean clearance in this group was close to that of the adalimumab controls $(9.12 \pm 2.81$ vs. 12.1 $\pm 3.81 \mathrm{~mL} / \mathrm{day} / \mathrm{kg}$ ).

ADA data for these offspring were consistent with the PK data and demonstrated that neonatal exposure to efalizumab did not confer immune tolerance to adalimumab: While predose samples were tested negative for ADAs, terminal samples were ADA positive in all 6 animals (>1.88 $\mu$ g-equivalent $/ \mathrm{mL})$.

Table II. Pharmacokinetic Parameters of Adalimumab Following Single IV Administration to Offspring after Immune Tolerance Induction

\begin{tabular}{|c|c|c|c|c|c|}
\hline \multirow[b]{2}{*}{ PK parameter } & \multicolumn{5}{|c|}{ Adalimumab dose in lactating mice $(\mathrm{mg} / \mathrm{kg})^{\mathrm{a}}$} \\
\hline & $-{ }^{\mathrm{b}}$ & 1 & 3 & 12 & 40 \\
\hline$\overline{\mathrm{CL}}(\mathrm{mL} /$ day $/ \mathrm{kg})$ & $12.1 \pm 3.81$ & $10.3 \pm 2.60$ & $8.77 \pm 2.67$ & $4.24 \pm 0.31 *$ & $7.20 \pm 4.87^{*}$ \\
\hline Vss $(\mathrm{mL} / \mathrm{kg})$ & $52.0 \pm 12.8$ & $66.3 \pm 10.6$ & $60.8 \pm 9.90$ & $85.0 \pm 10.8$ & $77.1 \pm 11.5$ \\
\hline $\mathrm{T} 1 / 2$ (day) & $2.20 \pm 1.07$ & $3.05 \pm 1.03$ & $4.16 \pm 1.62$ & $14.8 \pm 2.56^{*}$ & $10.3 \pm 8.16^{*}$ \\
\hline AUClast $(\mu \mathrm{g} \cdot$ day $/ \mathrm{mL})$ & $449 \pm 137$ & $510 \pm 126$ & $601 \pm 153$ & $887 \pm 62.0$ & $734 \pm 282$ \\
\hline AUCinf $(\mu \mathrm{g} \cdot$ day $/ \mathrm{mL})$ & $449 \pm 136$ & $512 \pm 126$ & $609 \pm 154$ & $1190 \pm 80.2$ & $963 \pm 493$ \\
\hline
\end{tabular}

Data presented as means \pm standard deviation

AUClast area under the concentration-time curve from zero to the last measurable concentration, AUCinf area under the concentration-time curve extrapolated to infinity, $C L$ clearance, $T 1 / 2$ terminal half-life, Vss volume of distribution in steady state

${ }^{a}$ Two subcutaneous administrations (within $24 \mathrm{~h}$ after delivery and $48 \mathrm{~h}$ after the first dose)

${ }^{b}$ Control

$* p<0.05$, statistically significant difference from control 


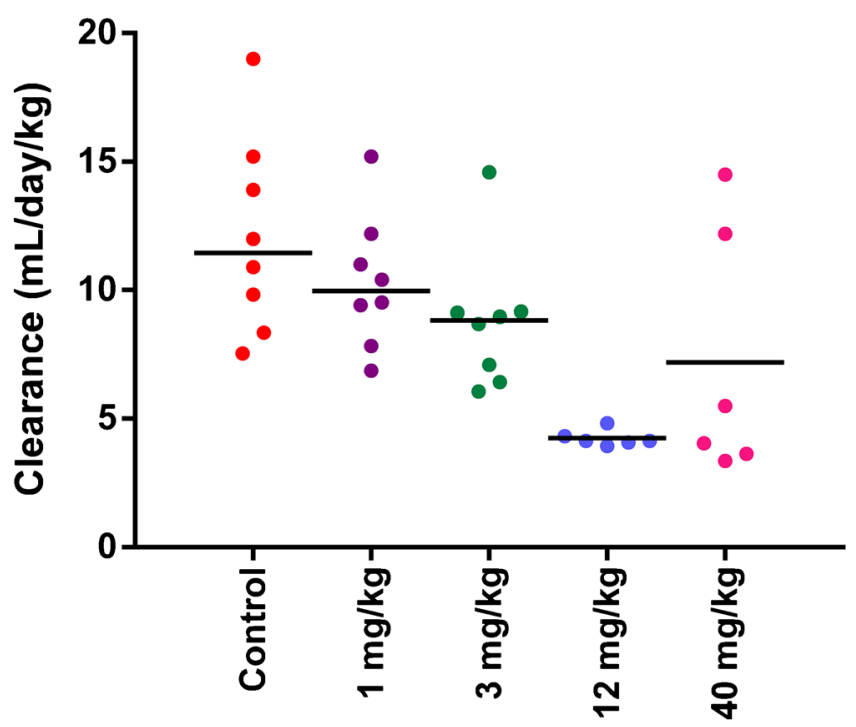

Dose in maternal mice $(\mathrm{mg} / \mathrm{kg})$

Fig. 2. Individual and mean clearance values of adalimumab after intravenous administration of $5 \mathrm{mg} / \mathrm{kg}$ to the offspring from mother mice treated with two subcutaneous doses of 0 (control), 1, 3, 12, and $40 \mathrm{mg} / \mathrm{kg}$ adalimumab administered after delivery

\section{DISCUSSION}

Exposing neonatal mice to an immunogenic $\mathrm{mAb}$ resulted in immune-tolerant adult mice and allowed a successful PK assessment of an immunogenic biologic without interference from immune-related accelerated clearance. We accomplished neonatal exposure by administration of a mAb to nursing mothers after delivery. Immunoglobulins like mAb are excreted in milk and absorbed from the intestine of suckling pups via the neonatal $\mathrm{Fc}$ receptor $(\mathrm{FcRn})$ in several species including mice (20). Therefore, such delivery mode to

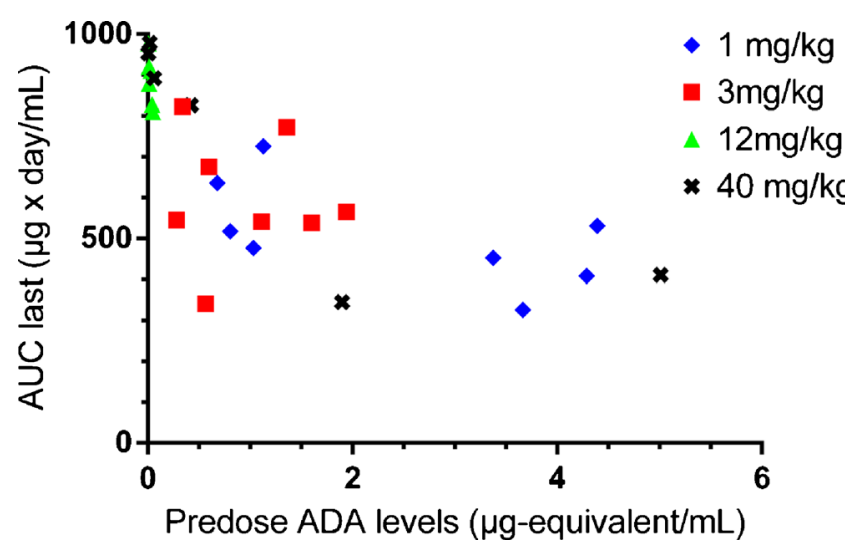

Fig. 3. Inverse relationship between individual predose antiadalimumab antibody levels and area under the plasma concentration-time curve of adalimumab after intravenous administration of $5 \mathrm{mg} / \mathrm{kg}$ to the offspring from mother mice treated with two subcutaneous doses of $1,3,12$, or $40 \mathrm{mg} / \mathrm{kg}$ adalimumab administered after delivery. The data suggest that predose anti-adalimumab antibody levels are predictive for degree of immune tolerance (Spearman Rank Correlation $r=-0.835 ; P<0.0001$ )

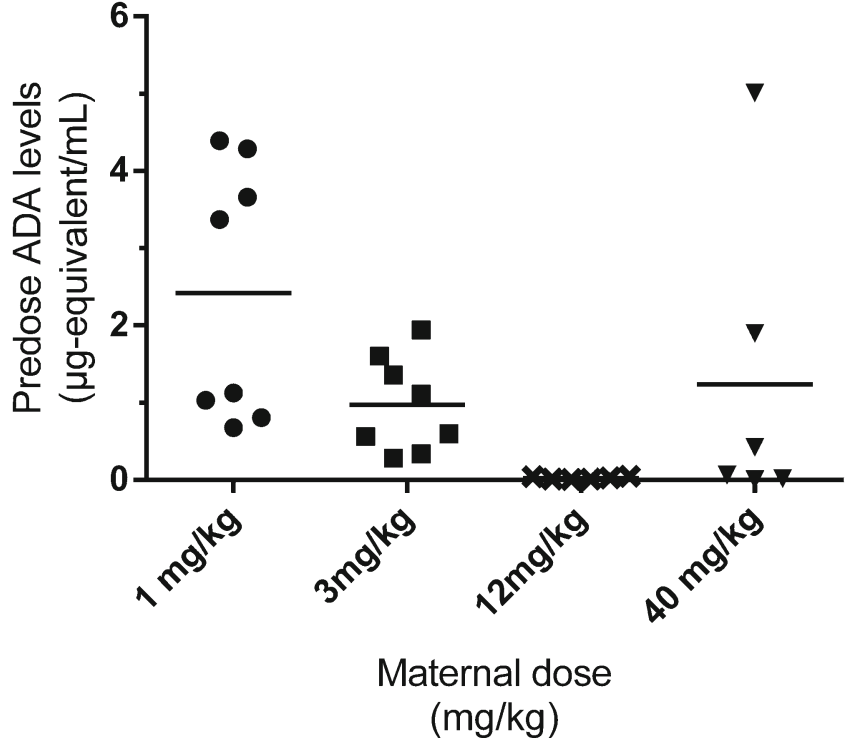

Fig. 4. Predose anti-adalimumab antibody levels in the offspring in relation to the maternal adalimumab dose: individual and mean predose anti-adalimumab antibody levels in the offspring from mother mice treated with two subcutaneous doses of $1,3,12$, or $40 \mathrm{mg} / \mathrm{kg}$ adalimumab administered after delivery

neonates is only applicable to $\mathrm{IgG}$ and $\mathrm{Fc}$-fusion proteins capable of FcRn binding. The chosen approach allows neonatal tolerogen exposure of newborn mice without direct tolerogen administration, thereby reducing the burden on the newborn animals.

After delivery, mother mice received two subcutaneous doses (48 $\mathrm{h}$ apart) of respective tolerogen. This dosing schedule was similar to that described by Halsey et al. and was not further optimized (15). We did not assess the exposure of lactating mice to adalimumab and efalizumab in the present study to reduce experimental burden on the mice. However, since both mAbs are well absorbed after subcutaneous administration in other species (SC bioavailability in humans: 64 and 56\%, respectively) $(21,22)$, the systemic exposure of nursing mice with subsequent $\mathrm{mAb}$ transfer to pups can be assumed. Moreover, the formation of ADA in several dose groups provides indirect evidence for successful $\mathrm{mAb}$ transfer to pups (see also below).

Adalimumab-treated mother mice developed ADA against adalimumab. Since endogenous mouse $\mathrm{IgG}$ is also transferred to suckling pups (20), the pups were probably also exposed to maternal ADA. It is, however, unclear, whether pups were also exposed to adalimumab-ADA immune complexes, which could have contributed to tolerance induction in addition to the free adalimumab. Notably, IgG immune complexes containing ovalbumin as antigen and transferred to mouse pups via milk have been shown to be more efficient than milk-born free antigen in inducing oral tolerance and preventing asthma (23). Ovalbumin-IgG immune complexes formed under excess of $\mathrm{IgG}$ have been shown to be excreted in mice via milk and to reach systemic circulation in nursed neonates (24). Bispecific antigens like adalimumab, however, may also form large, cross-linked immune complexes. It remains open whether such cross- 


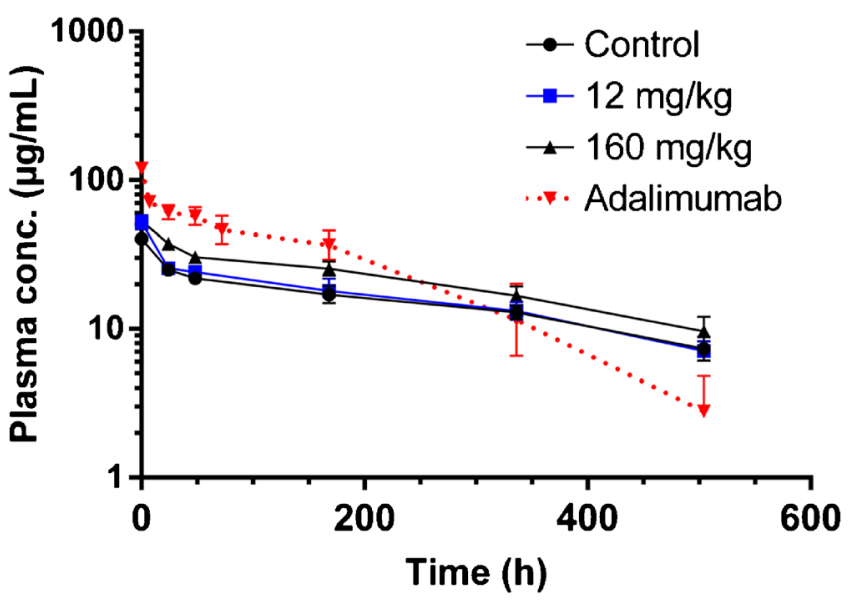

Fig. 5. Lack of immunogenicity of efalizumab and specificity of the immune tolerance induction: Mean plasma concentration-time curves of efalizumab after intravenous administration of $2 \mathrm{mg} / \mathrm{kg}$ to the offspring from mother mice treated with two subcutaneous doses of 0 (control), 12, and $160 \mathrm{mg} / \mathrm{kg}$ efalizumab administered after delivery, as well as mean plasma concentration-time curve of adalimumab after intravenous administration of $5 \mathrm{mg} / \mathrm{kg}$ adalimumab to the offspring from mother mice treated with two subcutaneous doses of $160 \mathrm{mg} / \mathrm{kg}$ efalizumab administered after delivery ( $\operatorname{mean}_{ \pm} \mathrm{SD}, n=5-8$ /group)

linked immune complexes are transferred to the nursed neonate via the FcRn pathway, as cross-linked immune complexes have been reported to undergo lysosomal breakdown rather than FcRn-mediated recycling/transcytosis (25).

The study results demonstrate tolerance induction for adalimumab in a maternal dose-dependent manner. On the basis of available data, it remains unclear whether there is a dose-dependent threshold for immune tolerance or a continuous dose-effect. Full immune tolerance was achieved at a maternal dose level of $12 \mathrm{mg} / \mathrm{kg}$. At a maternal dose level of $40 \mathrm{mg} / \mathrm{kg}$, however, tolerance induction failed in some offspring. Nevertheless, a bell-shaped relationship between maternal dose and tolerance induction appears to be unlikely, as the offspring mice without tolerance induction were all from the same mother mouse. Even among the offspring from this mother, one animal showed relatively low predose ADA levels, while another showed the highest predose ADA level among all animals. The reason for this unexpected finding is unknown. It is worth mentioning, however, that Komatsu et al. found no indication for a bell-shaped relationship between maternal $\mathrm{IgG}$ tolerogen dose and tolerance induction in mice (16).

The tolerogen dose required for tolerance induction may depend on mouse strain as well as on tolerogen. Komatsu and co-workers demonstrated that lower $\mathrm{IgG}$ doses are required for immune tolerance induction in $\mathrm{C} 57 \mathrm{BL} / 6$ mice as compared to $\mathrm{BALB} / \mathrm{c}$ mice (16). In their study, low single intravenous doses of human $\mathrm{IgG}$ in mothers, $0.5 \mu \mathrm{g}$ in $\mathrm{C} 57 \mathrm{BL} / 6$ and $50 \mu \mathrm{g}$ in BALB/c mice (equivalent to ca. 0.025 and $2.5 \mathrm{mg} / \mathrm{kg}$ ), were sufficient to induce tolerance in the offspring.

The PK study with adalimumab in the immune tolerant group enabled us to perform an accurate PK assessment in the absence of accelerated immune-mediated clearance. In the $12 \mathrm{mg} / \mathrm{kg}$ group, adalimumab exhibited a very low clearance $(4.24 \mathrm{~mL} / \mathrm{day} / \mathrm{kg})$, resulting in a long half-life of
14.8 days. This clearance was at the lower end of the reported range for therapeutic mAb clearance in mice of $\sim 3-16 \mathrm{~mL} /$ day/kg (26). In the PK assessment of immunogenic biotherapeutics in non-tolerant laboratory animals, the phase of immune-mediated accelerated clearance is usually disregarded and the terminal phase is defined from concentration-time points that precede the onset of the accelerated clearance (3). Such PK assessment for adalimumab in the control group yielded markedly higher clearance values due to an inappropriate assessment of the terminal elimination phase as a consequence of short observation time of 7 days and, thus, a misleading PK evaluation for adalimumab (data not shown). Importantly, the phase of accelerated clearance was not disregarded in the PK evaluation in the present study (see "MATERIALS AND METHODS") in order to better demonstrate PK differences across the dose groups.

In this study, we could demonstrate the beneficial effects of immune-tolerant test animals only for PK assessment for adalimumab. The second test compound, efalizumab, was non-immunogenic under our test conditions, and hence, we were not able to study tolerance induction to efalizumab. Dosing of adalimumab to the offspring from efalizumabtreated mothers confirmed the expected compound specificity of tolerance induction. The constant $\mathrm{IgG}$ sequences of adalimumab and efalizumab are very similar, differing only in two sites in the $\mathrm{CH} 3$ domain (EU site D356 vs E356 and L358 vs M358) (for sequences see http://www.drugbank.ca/ drugs/DB00051 for adalimumab and http://www.drugbank.ca/ drugs/DB00095 für efalizumab). Our experimental results suggest that the immunogenic epitope(s) of adalimumab are located in those sequences, where both molecules differ, i.e., either in variable regions or in the $\mathrm{CH} 3$ domain.

The microsampling technique $(20 \mu \mathrm{L}$ blood volume per sample) allowed serial blood sampling in an individual animal for analysis of both $\mathrm{mAb}$ and ADA levels. This approach helped us to assess and correlate PK results and ADA data for individual animals. A relevant fraction of the offspring from adalimumab-treated mothers was positive for ADA prior to adalimumab dosing and the level of predose ADAs correlated with the PK of adalimumab in the offspring. It would be interesting to understand whether the predose ADA in offspring are due to maternal transfer of ADA to offspring or whether they reflect an immune response against adalimumab in the offspring following exposure via milk. Although serial sampling starting at weaning would have addressed this question, we avoided any sampling on the offspring prior to adalimumab administration for experimental reasons. Circumstantial evidence, however, indicates that the predose ADA were formed in the offspring themselves: All adalimumab-treated maternal mice showed relevant ADA levels at weaning, whereas the predose ADA prevalence in offspring depended on the maternal adalimumab dose (offspring of mothers treated with $12 \mathrm{mg} / \mathrm{kg}$ had no predose ADA and offspring of mothers treated with 1 or $3 \mathrm{mg} / \mathrm{kg}$ showed marked ADA levels). The lack of predose ADA in the $12 \mathrm{mg} / \mathrm{kg}$ group suggests that the predose ADA in the offspring of other groups is formed in the offspring animals themselves. Of note, animals with no detectable ADA levels at predose also had ADA-negative terminal samples. Thus, predose ADA levels may allow pre- 
experimental assessment of the tolerance induction, lending themselves for a triage of test animals for successful tolerance induction prior to initiation of studies.

In the present study, we demonstrated successful use of neonatal immune tolerance induction to enable a PK study with a highly immunogenic mAb in mice. Although neonatal immune tolerance induction is well known in the literature, we are not aware of any reports on its use in the development of therapeutic mAbs. Neonatal immune tolerance induction has been described for rodents and rabbits following neonatal exposure to a protein $(15,16,27)$. Such studies following administration of a protein to neonates are apparently missing in non-human primates. In both non-human primates and dogs, however, neonatal immune tolerance induction was successfully used to facilitate gene therapy (28). Gene therapy in neonates of both species rendered them immune tolerant to the nonself protein formed from gene therapy.

Neonatal immune tolerance induction is of particular interest for studies with immunogenic proteins in mice. In mice, it takes only about 8 weeks for a newborn to reach the young adult stage, in which it can be used for subsequent studies. Such time frame is usually compatible with time frames of experimental planning in drug development, making the neonatal immune tolerance induction an attractive alternative to other approaches for tolerance induction in mice. Due to its antigen specificity, neonatal immune tolerance induction is particularly attractive for the studies that require otherwise a fully functional immune system.

Overall, the present study demonstrated the suitability of neonatal immune tolerance induction for a 4-week single dose study in 8 -week-old mice with a human mAb that is otherwise very immunogenic in laboratory animals. Further work will be required to explore the suitability of this approach for longer studies including multiple dose studies.

\section{ACKNOWLEDGMENTS}

The authors thank Veronique Dall'Asen, Christelle Rapp and Marie-Stella Gruyer for their help overseeing animal experiments, Markus Haak for his support in the conduct of bioanalytical assays, and Kay Stubenrauch for helpful discussions as well as bioanalytical reagent supply.

\section{REFERENCES}

1. Leach MW, Rottman JB, Hock MB, Finco D, Rojko JL, Beyer JC. Immunogenicity/hypersensitivity of biologics. Toxicol Pathol. 2014;42(1):293-300.

2. Frost H. Antibody-mediated side effects of recombinant proteins. Toxicology. 2005;209:155-60.

3. Richter WF, Gallati H, Schiller CD. Animal pharmacokinetics of the tumor necrosis factor receptor-immunoglobulin fusion protein lenercept and their extrapolation to humans. Drug Metab Dispos. 1999;27:21-5.

4. Tabrizi MA, Tseng CM, Roskos LK. Elimination mechanisms of therapeutic monoclonal antibodies. Drug Discov Today. 2006;11:81-8.

5. Ng CM, Loyet KM, Iyer S, Fielder PJ, Deng R. Modeling approach to investigate the effect of neonatal $\mathrm{Fc}$ receptor binding affinity and anti-therapeutic antibody on the pharmacokinetic of humanized monoclonal anti-tumor necrosis factor- $\alpha$
IgG antibody in cynomolgus monkey. Eur $\mathrm{J}$ Pharm Sci. 2014;51:51-8.

6. Junghans RP, Waldmann TA. Metabolism of Tac (IL2Ralpha): physiology of cell surface shedding and renal catabolism, and suppression of catabolism by antibody binding. J Exp Med. 1996;183:1587-602.

7. Alvarez HM, So OY, Hsieh S, Shinsky-Bjorde N, Ma H, Song Y, et al. Effects of PEGylation and immune complex formation on the pharmacokinetics and biodistribution of recombinant interleukin 10 in mice. Drug Metab Dispos. 2012;40:360-73.

8. ICH guideline S6 (R1) - preclinical safety evaluation of biotechnology-derived pharmaceuticals. June 2011. EMA/ CHMP/ICH/731268/1998. (http://www.ema.europa.eu/docs/ en_GB/document_library/Scientific_guideline/2009/09/ WC̄500002828.pdf)

9. Ageyama N, Hanazono Y, Shibata H, Ono F, Nagashima T, Ueda $\mathrm{Y}$, et al. Prevention of immune responses to human erythropoietin in cynomolgus monkeys (Macaca fascicularis). J Vet Med Sci. 2006;68:507-10.

10. Yan J, Xu L, Welsh AM, Chen D, Hazel T, Johe K, et al. Combined immunosuppressive agents or CD4 antibodies prolong survival of human neural stem cell grafts and improve disease outcomes in amyotrophic lateral sclerosis transgenic mice. Stem Cells. 2006;24:1976-85.

11. Yoshida H, Hashizume M, Suzuki M, Mihara M. Induction of high-dose tolerance to the rat anti-mouse IL-6 receptor antibody in NZB/NZW F1 mice. Rheumatol Int. 2011;31:1445-9.

12. Bessa J, Boeckle S, Beck H, Buckel T, Schlicht S, Ebeling M, et al. The immunogenicity of antibody aggregates in a novel transgenic mouse model. Pharm Res. 2015;32:2344-59.

13. Liblau RS, Tisch R, Shokat K, Yang X, Dumont N, Goodnow $\mathrm{CC}$, et al. Intravenous injection of soluble antigen induces thymic and peripheral T-cells apoptosis. Proc Natl Acad Sci U S A. 1996;93:3031-6.

14. Sakurai T, Takai R, Bürgin H, Shioda A, Sakamoto Y, Amano J, et al. The effects of interleukin-6 signal blockade on immune system, reproductive and skeletal development in juvenile mice. Birth Defects Res B Dev Reprod Toxicol. 2013;98:170-82.

15. Halsey JF, Benjamin DC. Induction of immunologic tolerance in nursing neonates by absorption of tolerogen from colostrum. J Immunol. 1976;116:1204-7.

16. Komatsu $\mathrm{T}$, Okao $\mathrm{M}$, Miyamoto $\mathrm{H}$, Chen $\mathrm{T}$, Shinka $\mathrm{S}$. Effects of early antigen exposure through lactation on later specific antibody responses in mice. J Immunol. 1988;141:2895-906.

17. Zheng Y, Tesar DB, Benincosa L, Birnböck H, Boswell CA, Bumbaca D, et al. Minipig as a potential translatable model for monoclonal antibody pharmacokinetics after intravenous and subcutaneous administration. MAbs. 2012;4:243-55.

18. Stubenrauch K, Wessels U, Lenz H. Evaluation of an immunoassay for human-specific quantitation of therapeutic antibodies in serum samples from non-human primates. J Pharm Biomed Anal. 2009;49(4):1003-8.

19. Stubenrauch K, Mackeben K, Vogel R, Heinrich J. Generic antidrug antibody assay with drug tolerance in serum samples from mice exposed to human antibodies. Anal Biochem. 2012;430(2):193-9.

20. Lobo ED, Hansen RJ, Balthasar JP. Antibody pharmacokinetics and pharmacodynamics. J Pharm Sci. 2004;93(11):2645-68.

21. Richter WF, Jacobsen B. Subcutaneous absorption of biotherapeutics: knowns and unknowns. Drug Metab Dispos. 2014;42(11):1881-9.

22. Ng CM, Joshi A, Dedrick RL, Garovoy MR, Bauer RJ. Pharmacokinetic-pharmacodynamic-efficacy analysis of efalizumab in patients with moderate to severe psoriasis. Pharm Res. 2005;22(7):1088-100.

23. Mosconi E, Rekima A, Seitz-Polski B, Kanda A, Fleury S, Tissandie E, et al. Breast milk immune complexes are potent inducers of oral tolerance in neonates and prevent asthma development. Mucosal Immunol. 2010;3:461-74.

24. Kim YW, Halsey JF. Metabolism and clearance of antibodyexcess immune complexes in lactating mice. J Immunol. 1982;129:619-622.25.

25. Weflen AW, Baier N, Tang QJ, Van den Hof M, Blumberg RS, Lencer WI, et al. Multivalent immune complexes divert FcRn to 
lysosomes by exclusion from recycling sorting tubules. Mol Biol Cell. 2013;24:2398-405.

26. Deng R, Iyer S, Theil FP, Mortensen DL, Fielder PJ, Prabhu S. Projecting human pharmacokinetics of therapeutic antibodies from nonclinical data: what have we learned? MAbs. 2011:3:61-6.
27. Rieger $\mathrm{CH}$, Gülden $\mathrm{P}$, Byrd DJ. Induction of specific tolerance to ingested soluble protein in neonatal rabbits. Immunobiology. 1981;160:330-9.

28. Hinderer C, Bell P, Louboutin JP, Zhu Y, Yu H, Lin G, et al. Neonatal systemic AAV induces tolerance to CNS gene therapy in MPS I dogs and nonhuman primates. Mol Ther. 2015;23:1298-307. 